\title{
Lirik Lagu “7 Rings” Ariana Grande Sebagai Representasi Gaya Hidup Hedonisme dan Konsumerisme: Suatu pemaknaan semiotika
}

\author{
Shafwan Nugraha ${ }^{1}$, Yati Heryati ${ }^{2}$, Iwan Adinugroho ${ }^{3}$ \\ 1,2,3 Universitas Muhammadiyah Mamuju \\ e-mail: ${ }^{1}$ shaf1_stiemm@yahoo.co.jp, ${ }^{2}$ heryati17@gmail.com, ${ }^{3}$ iwankolil@yahoo.com

\begin{tabular}{ccc}
\hline Diterima & Direvisi & Disetujui \\
$15-09-2021$ & $29-09-2021$ & $29-09-2021$ \\
\hline
\end{tabular}

\begin{abstract}
Abstrak - Pada 2019 silam, Ariana Grande, salah seorang penyanyi dan bintang pop dari Amerika Serikat merilis lagu berjudul "7 Rings" yang kemudian menjadi populer dan berada di puncak tangga lagu di berbagai negara. Grande menyebut bahwa lirik lagu tersebut melambangkan persahabatannya bersama ketujuh sahabatnya. Namun begitu, jika dibaca kembali, lirik lagu tersebut justru merepresentasikan gaya hidup masyarakat konsumerisme dan hedonisme. Penelitian ini berusaha mengungkap representasi perilaku konsumerisme dan eskapisme hedonistik tersebut dengan bantuan metode hermeneutika. Penelitian dilaksanakan dengan metodologi deskriptif-kualitatif. Sumber data penelitian adalah lirik lagu "7 Rings" yang dikomposisi oleh Ariana Grande, dkk. Data yang diperoleh kemudian dianalisis dengan bantuan metode semiotika Roland Barthes yang membuat interpretasi berdasarkan pemaknaan denotatif dan konotatif. Hasil analisis memperlihatkan bahwa beberapa kalimat lirik lagu "7 Rings" merupakan representasi perilaku konsumerisme dan hedonisme yang sangat mengagungkan uang dan kekayaan material sebagai sarana memuaskan diri. Meskipun Grande, dkk. menyatakan bahwa lagu tersebut merupakan lambang persahabatan dirinya dengan sahabatnya yang ikut menulis lirik, pada akhirnya para penyimak lagu tersebut juga menyadari bahwa lirik lagu tersebut tidak lebih dari narsisme materialistik yang mengagungkan kekayaan diri sendiri sebagai upaya menghibur diri. Adanya perbedaan interpretasi lirik ini memperlihatkan bahwa petanda dari pembacaan konotatif tidak terikat pada satu interpretasi melainkan bisa berbeda.
\end{abstract}

Abstract - In 2019, Ariana Grande, a singer and pop star from the United States released a song called "7 Rings" which later became popular and topped the charts in various countries. Grande said that the lyrics of the song symbolize her friendship with her seven best friends. However, after reading the lyric using semiotics, it actually can be considered as representation of the lifestyle of the consumerist and hedonistic society. This research tries to reveal the representation of consumerism behavior and hedonistic escapism with the help of hermeneutic methods. The research was carried out with a descriptive-qualitative methodology. The research data source is the lyrics of the song "7 Rings" which was composed by Ariana Grande, et al. The data obtained were then analyzed with the help of Roland Barthes' semiotic method which makes interpretations based on denotative and connotative meanings. The results of the analysis show that some of the lyrics of the song "7 Rings" are a representation of consumerism and hedonism behavior that highly exalts money and material wealth as a means of satisfying oneself. Although Grande, et al. stating that the song is a symbol of his friendship with his best friend who co-wrote the lyrics, in the end the listeners of the song also realized that the lyrics of the song were nothing more than materialistic narcissism that glorified one's own wealth as an effort to entertain themselves. The existence of different interpretations of the lyrics shows that the sign of connotative reading is not tied to one interpretation but can be different.

Kata kunci: hedonisme, konsumerisme, ariana grande, lagu pop

\section{PENDAHULUAN}

Sejak lama musik adalah sebuah produk budaya yang begitu lekat dengan kehidupan manusia. Di hampir setiap kebudayaan dapat ditemukan musik. Keeratan hubungan itu tentu tidak lepas dari fakta bahwa musik merupakan salah satu bentuk seni yang diciptakan manusia. Oleh karena begitu beragamnya kebudayaan manusia, beragam pula ragam musik yang bisa ditemui dalam kehidupan sehari-hari.
Di masyarakat saat ini, karya seni musik beragam jenisnya. Namun salah satu yang eksistensinya sangat populer adalah musik pop. Musik pop di masyarakat biasanya ditemukan dalam bentuk lagu pop, yaitu ragam musik pop yang diiringi lirik

Secara sekilas lagu populer seringkali dianggap sebagai sebuah karya seni yang bersifat menghibur (Sulastianto et al., 2006). Adorno (dalam Barker, 2016:47) bahkan menyebut musik pop sebagai sebuah musik yang sekadar dipoles, miskin orisinalitas, dan tidak membutuhkan kemampuan 
pencerapan musik yang tinggi oleh audiensnya. Pandangan seperti ini seolah sebuah simplifikasi dari suatu genre atau kelompok karya musik yang sebenarnya kompleks. Akan tetapi, belakangan banyak peneliti yang justru menemukan bahwa musik pop bukanlah sebuah eksistensi yang remeh. Data hasil survei Statista.com (2021) yang melibatkan 1.000 responden di Amerika Serikat menyebutkan bahwa $56.1 \%$ responden menyukai musik pop. Sementara itu di Indonesia, hasil survei yang dilakukan (Prasetio, 2013) yang mengambil siswa SMK di Yogyakarta sebagai sampel menyebutkan bahwa genre pop adalah genre musik yang disukai sebagian besar siswa SMK sebagai representasi generasi remaja $(51,47 \%)$. Data ini menunjukkan bahwa karena memiliki audiens yang besar dan hal itu berarti bahwa potensi ekonomi di balik produksi, distribusi, dan konsumsi musik pop tentu sangat besar. Namun favoritisme yang tinggi itu bukan sekadar representasi potensi ekonomi yang besar, melainkan juga sebagai representasi betapa besarnya pengaruh musik pop terhadap kehidupan sosial masyarakat secara umum, dan generasi muda secara khusus. Peneliti berpandangan potensi dan implikasi yang besar dari musik pop berkaitan dengan kemampuannya untuk menggaet audiens yang besar sekaligus eksistensinya sebagai produk budaya populer yang akhirnya ikut andil dalam mengukuhkan nilai-nilai budaya dan sosial yang lekat dengan kehidupan modern.

Seperti disebutkan sebelumnya, musik pop adalah musik yang lekat dengan lirik. Ketika menganalisis lagu, Tambayong (2011:36) menyebutkan bahwa lirik lagu adalah sebuah acuan verbal dari suatu musik yang dapat mengunjukkan kemahiran si pencipta musik berkreasi di dalam dimensi kebahasaan suatu musik, dan untuk memahaminya seseorang perlu menyimak baris demi baris, larik demi larik dari lirik lagu tersebut. Dari pernyataan itu, dapat dipahami bahwa analisis terhadap lirik lagu termasuk upaya mempelajari elemen bahasa dari suatu karya musik.

Sebagai elemen lagu yang berwujud satuan bahasa, lirik dapat digunakan sebagai alat pembawa pesan di dalam sebuah lagu. Seorang pendengar lagu dapat mencerap rasa sedih seseorang yang diselingkuhi dalam hubungan percintaan ketika mendengar kata-kata yang melambangkan kesedihan di dalam lirik lagu. Begitu pula ketika mendengarkan lirik lagu yang ceria dan menyemangati, seseorang dapat ikut merasa semangat dan ceria. Hal ini memperlihatkan bahwa lagu, melalui liriknya, dapat menjadi media yang menyampaikan, pesan, gagasan, bahkan ideologi. Pandangan ini sejalan dengan apa yang dikemukakan Zaid et al., (2021). Beberapa penelitian bahkan mengungkapkan berbagai ideologi bisa ditemukan di dalam lirik lagu. Penelitian (Aviandy \& Saleh, 2020) misalnya, mengungkapkan bahwa lirik lagu "Mama Anarxija" (Mama Anarki) adalah representasi pertentangan ideologi antara kelompok pemuda Uni Soviet yang menginginkan perubahan sosial dan kelompok generasi tua Uni Soviet yang saat itu berkuasa dalam pemerintahan dan ingin mempertahankan kondisi. Penelitian menarik lainnya dilakukan oleh (Setiowati \& Wahyuningtyas, 2011) yang menyimpulkan bahwa lirik lagu bisa dipahami dengan makna yang berbeda karena orang yang membaca atau mendengarkan lirik lagu tersebut memaknai kata-kata di dalam dengan pengalaman yang berbeda dan dengan ideologi yang berbeda.

Ariana Grande adalah salah seorang penyanyi, model, dan figur publik yang cukup digandrungi oleh remaja masa kini. Berdasarkan hasil survei dari YouGov (2021), sebuah lembaga riset pasar dari Inggris dan Amerika, 47\% responden memiliki opini positif, 33\% responden beropini netral, dan hanya $15 \%$ beropini negatif tentang Ariana Grande. Riset ini melibatkan 6.223 kuesioner yang dibagikan secara daring sehingga sampel responden yang diambil tidak terbatas di Inggris Raya semata, tetapi juga di daerah lain dari seluruh dunia. Dari seluruh responden tersebut, 95\% mengaku mengenal Ariana Grande. Sebagian besar yang menyukainya adalah kaum milenial.

Grande juga terbilang produktif dalam merilis karya. Sejak awal karir musiknya di 2013 hingga saat ini, Grande telah merilis lima album. Setiap tahun, kecuali 2015 dan 2017, Grande merilis album. Kemudian, pada 2019 silam Grande merilis sebuah lagu berjudul "7 Rings". Secara singkat, lagu ini berhasil meraih perhatian pasar dan bercokol di posisi-posisi tinggi tangga lagu (music chart) radioradio di seluruh dunia, tak terkecuali Indonesia. Produktivitas Grande, penampilannya yang mampu menjadi trend setter, dan kepribadian yang menarik menjadi pendorong utama pengaruhnya dalam kancah popularitas figur di kalangan generasi muda. Grande menceritakan asal-muasal penciptaan lirik lagu "7 Rings" dalam cuitan berikut.

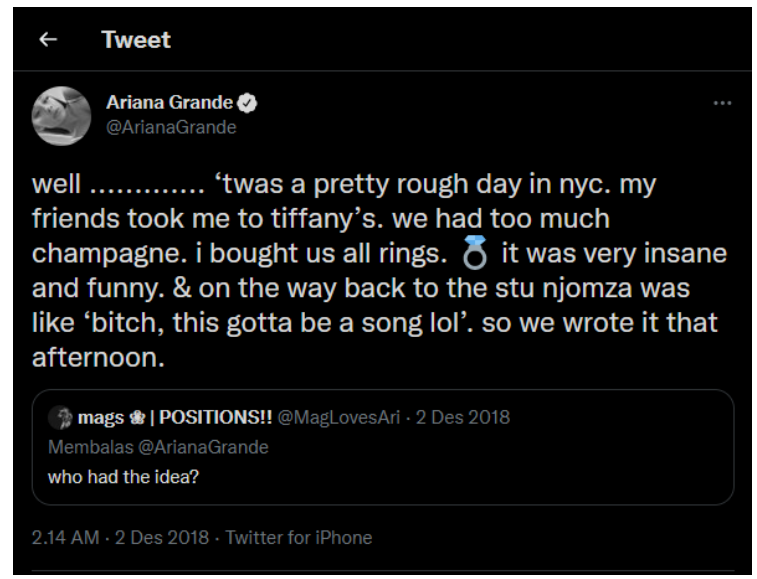

Sumber: Twitter Ariana Grande (2018) 
Gambar 1. Kutipan Tweet Grande tentang penciptaan lirik "7 Rings".

Dalam sebuah artikel dari situs web Elle, reporter Bowenbank (2019) memaparkan latar belakang penciptaan lirik lagu "7 Rings" berhubungan dengan kejadian batalnya tunangan Grande dengan mantan kekasihnya, Pete Davidson. Setelah mengembalikan cincin tunangannya, Grande bersama rekan-rekan perempuannya pergi mengunjungi Tiffany, co., sebuah toko perhiasan mewah yang terkenal di New York. Di toko tersebut Grande ditawari minuman sampanye yang sangat banyak, kemudian diminumnya hingga mabuk, dan kemudian Grande membelikan tujuh cincin tunangan untuk dirinya dan keenam temannya yang pergi bersama. Pada akhirnya Grande menyebut ketujuh cincin tunangan itu menjadi simbol persahabatan di antara dirinya dengan keenam sahabatnya yang dibelikan cincin.

Jika dibaca sekilas, dapat dimengerti alasan Grande menyebut "7 Rings" adalah lagu tentang persahabatan dirinya dengan kawan-kawannya. Namun begitu, jika dibaca kembali dengan metode pembacaan yang lebih kritis dan analitis, lirik lagu "7 Rings" bisa dimaknai sebagai sebuah representasi perilaku konsumerisme dan gaya hidup hedonisme. Yang dimaksud dengan perilaku konsumerisme adalah perilaku-perilaku manusia yang menganggap bahwa barang mewah merupakan ukuran kebahagiaan manusia. Sementara itu, gaya hidup hedonisme adalah gaya hidup yang mengejar kesenangan material sebagai tujuan utama hidup. Kedua konsep tersebut sangat berkaitan erat karena sama-sama berkiblat pada sikap manusia yang mengagung-agungkan harta benda sebagai simbol dan sumber kebahagiaan hidupnya.

Salah satu bagian lirik "7 Rings" yang mengindikasikan representasi ini misalnya bisa ditemukan pada larik-larik bait kelima seperti dijabarkan pada Tabel 1 berikut.

Tabel 1. Contoh data lirik

\begin{tabular}{|l|l|}
\hline Lirik Asli & Terjemahan \\
\hline Whoever said money & Siapapun yang \\
can't solve your & mengatakan uang tak \\
problems/ & bisa menyelesaikan \\
Must not have had & masalah/ \\
enough money to & Pasti tidak punya \\
solve 'em/ & uang yang cukup \\
They say, "Which & untuk menyelesaikan \\
one?" I say, "Nah, I & masalah/ \\
want all of 'em"/ & Mereka bilang, \\
Happiness is the & "(Mau) yang mana?" \\
same price as red & Kubilang, "Tidak, \\
bottoms & aku mau semuanya"/ \\
& Harga kesenangan \\
\hline
\end{tabular}

\begin{tabular}{|l|l|}
\hline & $\begin{array}{l}\text { sama dengan sepatu } \\
\text { sol merah (yang } \\
\text { harganya sangat } \\
\text { mahal)/ }\end{array}$ \\
\hline
\end{tabular}

Sumber: Data primer, 2021

Pada penggalan lirik tersebut, terdapat kalimat yang berbunyi "Whoever said money can't solve your problem//Must not have had enough money to solve 'em". Makna kalimat tersebut menolak gagasan bahwa uang tidak bisa menyelesaikan setiap masalah. Kalimat ini menegaskan bahwa uang justru bisa menyelesaikan masalah, selama kita memiliki uang yang cukup. Orientasi penyelesaian masalah dengan menggunakan uang seperti ini adalah salah satu contoh perilaku konsumerisme.

Dari paparan tersebut, penelitian ini diarahkan untuk menjawab masalah pokok, yaitu bagaimana lirik lagu "7 Rings" merepresentasikan perilaku konsumerisme dan gaya hidup hedonisme? Dengan demikian, dapat pula dirumuskan bahwa tujuan penelitian ini adalah mendeskripsikan cara lirik lagu "7 Rings" merepresentasikan perilaku konsumerisme dan gaya hidup hedonisme.

\section{Hedonisme}

Hedonisme berasal dari kata bahasa Yunani hedonismos, yang berarti 'kesenangan'. Akar katanya adalah hedus 'manis' dan akhiran -ismos 'paham' sehingga secara sederhana dipahami sebagai paham atau cara pandang hidup yang mengutamakan kesenangan. Dalam KBBI V, hedonisme diartikan "pandangan yang menganggap kesenangan dan kenikmatan materi sebagai tujuan utama dalam hidup". Sementara itu, menurut Armstrong dalam (Ichsanuddin \& Purnomo, 2021:6) mendefinisikan hedonisme sebagai "pola hidup yang aktivitasnya mencari kesenangan hidup, seperti menghabiskan waktu di luar rumah, lebih banyak bermain, senang pada keramaian kota, senang membeli barang mahal yang disenanginya, serta selalu ingin menjadi pusat perhatian." Definisidefinisi tersebut mengantarkan pada suatu pemahaman bahwa hedonisme merupakan sebuah gaya, cara pandang, atau pola kehidupan yang cenderung mengejar atau mengutamakan kesenangan sebagai dasar bertindak dan bersikap.

Di dalam bagian pengantar bukunya, Feldman (2004) menjelaskan bahwa hedonisme adalah sebuah konsep yang umurnya sudah sangat lama. Plato dan Aristoteles sudah pernah membahas hal ini dalam komentarnya terhadap pemikiran Socrates. Sejak masa filsuf Yunani kuno masih konsep ini sudah ada dan diperdebatkan, diterima kemudian ditolak, dibangkitkan kembali dan diredam, begitu sepanjang sejarah. 
Sejak lama, konsep hedonisme memang sudah dipandang negatif, tetapi bukan berarti tidak memiliki pendukung. (Feldman, 2004) menyebutkan bahwa konsep hedonisme seringkali disalahpahami karena hanya dipandang sebagai pemikiran yang materialistik, cenderung eskapis-menghindari kenyataan bahwa kehidupan itu tidak selamanya tentang kesenangan, ada pula kesedihan dan kedukaan. Namun begitu, tidak dapat dimungkiri bahwa ada suatu sisi di dalam diri manusia yang selalu mendorongnya untuk mencari kesenangan atau hal-hal yang cenderung menyenangkan ketimbang menerima hal yang tidak menyenangkan.

Pandangan klasik hedonisme dibawa oleh pandangan kaum Kyrenik, yaitu aliran filsafat yang dirintis oleh salah satu murid Socrates yang bernama Aristippus dari Kyrenia. Aliran Kyrenik adalah aliran filsafat sensual, yaitu filsafat yang mengutamakan penginderaan suatu objek. Pandangan hedonisme aliran Kyrenik yang diajarkan Aristippus menganggap bahwa setiap bentuk kesenangan, baik fisik maupun mental, adalah hal yang baik, meskipun bentuk kesenangan fisik lebih intens daripada kesenangan mental dan nilai intrinsik kehidupan ditentukan dari akumulasi intrinsik kesenangan yang didapatkan selama hidupnya (Feldman, 2004).

Pandangan yang agak berbeda tentang hedonisme diusung oleh filsuf Yunani bernama Epicurus (atau Epikuros). Konsep hedonisme yang diajarkan Epicurus berbeda dari pendahulunya. Ketika Aristippus berpandangan bahwa untuk mencapai kepuasan hidup kita harus memuaskan diri dengan kesenangan-kesenangan terutama kesenangan fisik (karena nilai intrinsiknya lebih tinggi daripada kesenangan mental semata), Epicurus berpandangan lebih moderat. Di dalam pandangan Epicurus, kesenangan adalah ketiadaan rasa sakit atau penderitaan yang dirasakan seseorang (Feldman, 2004:92). Artinya, untuk hidup bahagia dan menjalani hidup yang bermakna, seseorang tidak perlu mengejar kesenangan dengan berfoya-foya, melainkan dengan hidup secukupnya, tidak perlu berlebihan.

Kedua pandangan hedonisme ini selanjutnya diwariskan ke filsuf-filsuf dan masyarakatmasyarakat lainnya sepanjang perjalanan sejarah dan peradaban manusia. Seiring dengan berjalannya waktu, berkembangnya dinamika sosial dan ekonomi manusia, hedonisme lantas bangkit kembali. Kali ini hedonisme lahir berkat dorongan gaya hidup lainnya yang muncul sebagai konsekuensi dari revolusi industri, sistem ekonomi menjadi ekonomi kapitalistik, serta segala macam kemudahan dan kepraktisan yang didukung oleh semakin banyaknya bermunculan teknologi baru: konsumerisme.

\section{Konsumerisme}

Istilah konsumerisme juga merupakan istilah serapan yang berasal dari bahasa Inggris consumerism. Dalam KBBI V, istilah konsumerisme didefinisikan "paham atau gaya hidup yang menganggap barang-barang (mewah) sebagai ukuran kebahagiaan, kesenangan, dan sebagainya; gaya hidup yang tidak hemat."

Konsumerisme juga merupakan kata serapan dari bahasa Inggris, consumerism. Istilah tersebut memiliki akar kata yang sama dengan consumption 'konsumsi', yaitu to consume 'mengonsumsi'. Bauman (2007) berpendapat bahwa manusia, apalagi pada hakikatnya sebagai makhluk biologis, tidak bisa melepaskan diri dari kegiatan konsumsi karena dengan mengonsumsilah kita bertahan hidup. Namun begitu, kegiatan mengonsumsi yang berlebihan, mengonsumsi hal yang sebenarnya tidak atau belum kita butuhkan adalah hal yang dapat mendatangkan kerugian daripada manfaat karena seperti dikemukakan (Kurniullah et al., 2021:42) dapat menyebabkan orang-orang menjadi boros, malas bekerja, menurunnya semangat juang, dan membuang-buang sumber daya.

Konsumerisme sebagai sebuah gaya hidup lekat pada masyarakat yang berideologi sosialekonomi kapitalistik. Piliang, (2011:117) berpandangan bahwa ekonomi kapitalistik bukan saja pandangan dan sistem ekonomi yang memperdagangkan barang atau jasa, melainkan justru mengomodifikasi hasrat, godaan, atau rayuan yang menarik di mata konsumen, sehingga masyarakat sebagai konsumen tidak lagi termotivasi untuk mengonsumsi barang atas dasar fungsi atau manfaatnya, melainkan untuk memenuhi hasrat, karena tergoda oleh rayuan, tentang nilai-nilai bahkan ideologi tertentu yang disematkan oleh produsen kepada suatu barang. Ketika suatu produk tidak lagi bisa dijual sebagai sebuah barang atau jasa yang bernilai karena manfaatnya, setidaknya produk itu bisa dijual karena konsumen ingin memilikinya dengan minat tertentu atau untuk memuaskan hasrat tertentu semata. Dengan terpenuhinya hasrat tersebut, konsumen memuaskan dirinya sekaligus menemukan kesenangan, karena merasa hal yang dibutuhkannya tercukupi. Padahal, hal yang dibutuhkan itu bukan berdasarkan manfaatnya melainkan berdasarkan hasrat yang menggodanya. (Sudjatmiko, 2007) merangkum fenomena ini dengan mengatakan, "Manusia tidak hanya ditawari apa yang mereka butuhkan (what they needed), melainkan apa pula yang mereka harapkan (what they desired)."

Dari paparan ini, dapat ditarik pemahaman bahwa konsumerisme adalah sebuah sikap atau gaya hidup yang lekat pula hubungannya dengan upaya pemenuhan hasrat dalam rangka pemuasan 
kebutuhan hidup atau mencari kepuasan dan kesenangan hidup. Ini berarti konsumerisme memang berkaitan erat dengan filosofi hedonisme. Namun jika dikaitkan dengan pembandingan hedonisme yang telah peneliti ungkapkan di bagian sebelumnya, sikap atau gaya hidup konsumerisme cenderung mengarah pada hedonisme materialistik Aristippus.

Perilaku-perilaku konsumerisme bisa ditemukan di kehidupan sehari-hari masyarakat Indonesia, apalagi masyarakat Amerika Serikat yang sangat kental dengan budaya, sosial, dan ekonomi kapitalistik. Contoh perilaku yang paling simpel dari gaya hidup konsumerisme adalah belanja secara berlebihan, dalam artian bisa berlebihan dari jumlah atau berlebihan dari jenis. Contohnya, seseorang yang setiap bulan membeli sepatu baru meskipun sepatu sebelumnya masih layak pakai. Ia kerap tergoda pada gambar-gambar sepatu yang warnawarni, dengan desain keren, dan harga yang murah. Dasar pembelian sepatu bagi orang tersebut bukan lagi fungsional sepatu sebagai alas kaki atau busana yang melindungi kaki, melainkan karena tergoda akan model sepatu terbaru, yang mengikuti tren, dan didorong pula oleh harga yang relatif murah karena status "promo". Pada akhirnya sepatu-sepatu yang beraneka ragam dibeli setiap bulan itu bertumpuk di rak sepatu.

Konsekuensi dari perilaku membeli barang secara berlebihan seperti diilustrasikan tadi adalah pengeluaran uang dalam jumlah besar dan berlebihan pula. Dengan kata lain, kecenderungan berfoya-foya, membuang-buang uang bukan demi kepentingan fungsional melainkan untuk memuaskan diri. Piliang (2011) meminjam istilah Baudrillard yang menyebut bahwa masyarakat konsumerisme seringkali tenggelam dalam ekstasi, yaitu "Kondisi mental dan spiritual yang berpusar secara spiral, sampai pada satu titik ia kehilangan setiap makna, dan memancar sebagai pribadi yang hampa." Dalam perilaku konsumerisme, makna yang hilang itu adalah fungsionalitas dari objek yang dibeli atau didapatkan dengan uang. Sehubungan dengan itu, Piliang (2011) mengutip pandangan Porrit yang menyebutkan bahwa "gaya hidup konsumerisme adalah gaya hidup yang merayakan penampilan, status dan prestise diri melalui konsumsi”.

Contoh perilaku lainnya adalah perilaku impulse buying atau pembelian impulsif, yaitu perilaku membeli barang secara tiba-tiba, tanpa perencanaan atau pertimbangan yang baik. Pembelian barang memang bisa saja terjadi secara tiba-tiba, misalnya membeli perban dan obat-obatan karena ada kecelakaan atau membeli bahan makanan karena ada bencana alam. Namun begitu, perilaku pembelian impulsif berbeda dari pembelian secara tiba-tiba yang disebabkan adanya kebutuhan fungsional. Perilaku pembelian impulsif dimotivasi oleh keinginan, hasrat, atau dorongan kuat yang justru cenderung foya-foya, dan hanya untuk memuaskan diri sendiri. Dengan kata lain, perilaku pembelian impulsif terjadi karena kurangnya kemampuan seseorang menahan diri untuk tidak tergoda atau terangsang oleh hasrat membeli yang tiba-tiba.

\section{METODOLOGI PENELITIAN}

Penelitian ini dilaksanakan sebagai sebuah penelitian deskriptif-kualitatif. Penelitian ini mengumpulkan data primer berupa data kualitatif, dengan peneliti sebagai instrumen utama, dan membuat analisis secara induktif. Penelitian ini juga bertujuan memahami fenomena representasi perilaku dan gaya hidup masyarakat di dalam lirik lagu sehingga sejalan dengan pemahaman yang diberikan Moleong (2006) tentang penelitian kualitatif. Penelitian ini juga merupakan penelitian deskriptif karena bertujuan membuat deskripsi atau gambaran tentang sistem tanda yang ada dalam lirik lagu "7 Rings" Ariana Grande, sebagaimana penjelasan (Djajasudarma, 2010:6) tentang tujuan penelitian deskriptif yang membuat deskripsi atau gambaran secara sistematis.

Sumber data dalam penelitian ini adalah lirik lagu "7 Rings" yang dinyanyikan oleh Ariana Grande. Lirik lagu ini dikomposisi oleh Grande sendiri bersama enam orang kawannya yang lain, yaitu Victoria Monét, Courtney Chipolone, Alexa Luria, Tayla Parx, Njomza Vitia dan Kaydence Krysiuk. Lagu ini merupakan bagian dari album "thank u, next" yang dirilis pada 2019.

Teknik pengumpulan data yang digunakan adalah studi dokumentatif atau teknik kepustakaan. Peneliti mengumpulkan lirik lagu "7 Rings" dalam bahasa aslinya, yaitu bahasa Inggris, kemudian melakukan pembacaan dan penerjemahan larik per larik. Penerjemahan dilakukan untuk mempermudah pemahaman arti denotatif tiap larik.

Selanjutnya, dalam tahap analisis data, peneliti melacak kata-kata, frasa, atau kalimat yang menjadi simbol representasi gaya hidup hedonisme atau konsumerisme di dalam lirik lagu. Simbolsimbol representamen tersebut dianalisis dan diinterpretasi dalam kerangka analisis semiotika dikotomis Roland Barthes.

Model analisis semiotika Barthes adalah salah satu dari beberapa model analisis semiotika atau semiologi. Model analisis ini berangkat dari pemahaman Barthes terhadap sistem hubungan antara tanda dan makna yang digagas oleh Ferdinand de Saussure yang dikenal sebagai "bapak linguistik". 
Saussure mengembangkan sistem tanda-petanda antara kata dengan makna kata. Barthes mengembangkan sistem hubungan itu dengan menambahkan bahwa penghubungan makna antara tanda dan petanda tidak hanya berlangsung satu kali, namun berlanjut. Maka dari itulah, dalam model analisis pemaknaan tandanya, Barthes membuat pemaknaan denotasi dan pemaknaan konotasi. Adanya dua diemensi sistem hubungan tanda ini juga yang menjadikan analisis Barthes dikenal pula dengan istilah semiotika dikotomis.

Pemaknaan denotasi dalam semiotika Barthes terjadi ketika sebuah tanda dipahami sebagai suatu makna. Sebagai contoh, ketika disebutkan kata katana dan yang terbayang adalah pedang tradisional Jepang, maka pemaknaan tersebut adalah pemaknaan denotatif. Pemaknaan konotasi adalah ketika pemaknaan dari suatu tanda bersifat implisit, tidak langsung, tidak pasti, sehingga bisa dimaknai berbagai macam karena pemaknaan itu bisa dikaitkan dengan berbagai aspek (Piliang \& Jaelani, 2018). Misalnya, ketika seseorang melihat gambar pedang katana kemudian yang terpikir justru adalah pemandangan negara Jepang, kartun (anime) atau lagu populer berbahasa Jepang, pemaknaan yang dilakukan adalah pemaknaan konotatif.

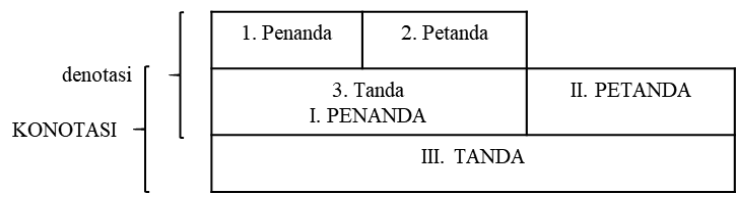

Gambar 2. Peta makna semiotika dikotomis Barthes

Dalam penelitian ini, tanda-tanda yang ditemukan dalam lirik lagu "7 Rings" dianalisis dalam kerangka dimensi notasional, yaitu analisis secara denotatif dan konotatif. Setiap pemaknaan dideskripsikan, kemudian pada simpulan analisis dibuatkan semacam peta makna yang memperlihatkan pemaknaan denotatif dan konotatif dari tanda-tanda yang ditemukan.

\section{HASIL DAN PEMBAHASAN}

Setelah membaca dan mempelajari teks lirik lagu "7 Rings" Ariana Grande, terlihat bahwa lirik lagu tersebut terdiri dari 8 bait. Setiap bait menjadi bagian dari struktur lirik, antara lain bagian verse, pre-chorus, dan chorus. Dari 8 bait tersebut, peneliti memilah beberapa bagian bait atau larik yang mengandung kata, frasa, atau kalimat yang maknanya merepresentasikan gaya hidup hedonisme dan konsumerisme. Berikut ini adalah transkripsi lirik lagu "7 Rings" yang dinyanyikan Ariana Grande.
[Verse 1]

Yeah, breakfast at Tiffany's and bottles of bubbles

Girls with tattoos who like getting in trouble

Lashes and diamonds, ATM machines

Buy myself all of my favorite things (Yeah)

Been through some bad shit, I should be a sad bitch Who woulda thought it'd turn me to a savage?

Rather be tied up with calls and not strings Write my own checks like I write what I sing, yeah (Yeah)

\section{[Pre-Chorus]}

My wrist, stop watchin', my neck is flossy

Make big deposits, my gloss is poppin'

You like my hair? Gee, thanks, just bought it

I see it, I like it, I want it, I got it (Yeah)

[Chorus]

I want it, I got it, I want it, I got it

I want it, I got it, I want it, I got it

You like my hair? Gee, thanks, just bought it

I see it, I like it, I want it, I got it (Yep)

[Verse 2]

Wearing a ring, but ain't gon' be no "Mrs." Bought matching diamonds for six of my bitches

I'd rather spoil all my friends with my riches

Think retail therapy my new addiction

Whoever said money can't solve your problems

Must not have had enough money to solve 'em

They say, "Which one?" I say, "Nah, I want all of 'em"

Happiness is the same price as red-bottoms

[Pre-Chorus]

My smile is beamin' (Yeah), my skin is gleamin' (Is gleamin')

The way it shine, I know you've seen it (You've seen it)

I bought a crib just for (Just for) the closet (Closet)

Both his and hers, I want it, I got it, yeah

[Chorus]

I want it, I got it, I want it, I got it

I want it, I got it, I want it, I got it (Baby)

You like my hair? Gee, thanks, just bought it (Oh yeah)

I see it, I like it, I want it, I got it (Yep)

[Verse 3]

Yeah, my receipts be lookin' like phone numbers

If it ain't money, then wrong number

Black card is my business card

The way it be settin' the tone for me

I don't mean to brag, but I be like, "Put it in the bag, "yeah

When you see them racks, they stacked up like my 
ass, yeah

Shoot, go from the store to the booth

Make it all back in one loop, gimme the loot

Never mind, I got the juice

Nothing but net when we shoot

Look at my neck, look at my jet

Ain't got enough money to pay me respect

Ain't no budget when I'm on the set

If I like it, then that's what I get, yeah

\section{[Chorus]}

I want it, I got it, I want it, I got it (Oh yeah)

I want it, I got it, I want it, I got it (Oh yeah, yeah)

You like my hair? Gee, thanks, just bought it

I see it, I like it, I want it, I got it (I see, yep)

\section{Analisis Bait I}

Pada bait ini ditemukan larik berbunyi "Breakfast at Tiffany's and bottles of bubbles". Pada larik tersebut, ditemukan kata Tiffany's yang merujuk pada nama suatu toko perhiasan yang sudah beroperasi sejak lama di New York yang bernama Tiffany \& Co. Meskipun sejatinya toko ini berjualan perhiasan, belakangan toko ini juga membuka layanan kafe yang diperuntukkan bagi pengunjung toko perhiasannya. Jika dianalisis secara konotasi, kata Tiffany yang merujuk pada sebuah toko perhiasan tentu berhubungan dengan konsep gaya hidup hedonisme dan konsumerisme yang mengejar kesenangan dunia dan materi.

Di larik keempat, didapatkan kalimat "Buy myself all of my favorite things." Jika diterjemahkan, kalimat ini bisa dartikan, 'Membelikan diriku sendiri segala hal yang kusukai.' Secara denotatif, kalimat ini menyebutkan tindakan membeli barang-barang yang berlebihan. Secara konotatif, tindakan pembelian barang yang berlebihan seperti itu merujuk pada perilaku konsumerisme yang seperti disebutkan (Scarpi, 2020).

\section{Analisis Bait II}

Pada larik ke ditemukan kalimat "Write my own checks like I write what I sing." Kalimat ini jika diterjemahkan kalimat ini bisa diartikan '(Aku) menulis cekku seperti aku menulis yang kunyanyikan.' Pemaknaan secara denotatif kalimat tersebut menggambarkan rasa bebas seseorang membelanjakan uangnya. Sementara pada pemaknaan konotatif, kalimat tersebut dapat diinterpretasi sebagai simbolisasi perilaku orang yang tidak banyak berpikir ketika mengeluarkan uang. "Menulis cek" adalah perilaku yang menjadi simbol kegiatan mengeluarkan uang, yang lebih jauh dapat dipahami sebagai hal yang dilakukan dalam rangka membelanjakan sesuatu. Ketika aktivitas menulis cek dilakukan dengan rasa bebas, tanpa rasa terbatas atau khawatir uang itu habis, orang tersebut merasa bahwa berbelanja merupakan sesuatu yang wajar, tidak perlu banyak dipikirkan, bahkan bisa dilakukan sebanyak-banyaknya.

\section{Analisis Bait III}

Pada Bait III ditemukan kalimat larik, "You like my hair? Gee, thanks, just bought it." Jika diterjemahkan, larik ini dapat diterjemahkan menjadi 'Kau suka rambutku? Terima kasih, aku baru saja membelinya.' Secara denotatif, larik ini menyebutkan seseorang yang mewujudkan penampilannya dengan cara membeli. "Membeli rambut" bisa dipahami sebagai penataan gaya atau perawatan rambut di salon atau tempat perawatan rambut. Dalam pemaknaan konotatif, larik ini merepresentasikan perilaku orang yang mewujudkan penampilan dirinya melalui kekuatan uang. Ini adalah representasi fenomena yang ramai terjadi belakangan ini di masyarakat kita: mengubah penampilan dengan membayar. Perempuan yang merasa penampilannya kurang cantik bisa meminta agar dipercantik di salon. Lelaki yang merasa dirinya kurang rupawan bisa melakukan upgrade penampilan yang sama, tentunya dengan membayar jasa menggunakan uang. Jika merasa kulit kurang putih, orang bisa membeli krim, serum, obat-obatan atau bahkan terapi pemutihan kulit. Jika merasa hidung kurang mancung, orang bisa operasi memancungkan hidung. Semua itu tentunya bisa dicapai dengan membelanjakan uang-jasa salon harus dibayar, obat-obatan perlu dibeli, dan operasi tentu keluar uang. Hal ini sejalan dengan pendapat Piliang, (2011:95) yang menyebutkan bahwa estetika fisik dan kesehatan tubuh memang merupakan bagian penting produksi dan promosi komoditi bagi masyarakat konsumer.

Larik terakhir bait III berbunyi "I see it, I like it, I want it, I got it" yang jika diterjemahkan dapat diartikan, "Aku melihatnya, aku menyukainya, aku menginginkannya, aku mendapatkannya". Secara denotatif makna kalimat ini mewakili perilaku seseorang yang selalu membelanjakan uang untuk suatu hal bukan karena fungsi dan manfaat hal tersebut, melainkan hanya karena dia menyukainya dan menginginkannya. Motivasi pembelian orang tersebut bukan lagi berbasis kebutuhan melainkan berbasis keinginan. Secara konotatif, perilaku yang digambarkan dalam kalimat tersebut merepresentasikan perilaku impulse buying yang seperti disebutkan pada bagian sebelumnya adalah salah satu contoh perilaku gaya hidup konsumerisme. 


\section{Analisis Bait IV}

Bait IV lirik lagu "7 Rings" adalah bagian chorus yang isinya diulang beberapa kali sepanjang lagu tersebut dinyanyikan. Isi bait IV diulang pula pada bait VIII dan XI. Pada bait-bait tersebut terdapat pula kalimat "I want it, I got it" yang merupakan penggalan dari larik terakhir bait III. Dengan hubungan referensi tersebut, dapat dipahami secara denotatif bahwa kalimat "I want it, I got it" dapat dimaknai secara konotatif sama dengan larik terakhir bait III, yaitu menjadi representasi perilaku impulse buying yang merupakan salah satu perilaku sikap konsumerisme. Adanya perulangan kata dengan jumlah banyak dapat dimaknai sebagai penegasan atau penguatan sekaligus legitimasi bahwa sikap konsumerisme yang dilakukan bukanlah hal yang salah, akan terus dilakukan, karena sudah menjadi cara pandang dan prinsip hidup.

\section{Analisis Bait V}

Bait V lirik lagu "7 Rings" adalah bait yang menarik karena hampir setiap lariknya merepresentasikan gaya hidup hedonisme dan perilaku konsumerisme. Pada larik kedua, terdapat kalimat "Bought matching diamonds for six of my bitches". Penerjemahan kalimat ini sedikit menarik karena adanya pilihan kata bitches di akhir kalimat. Kata bitches adalah bentuk nomina jamak dari bitch yang standarnya diterjemahkan ke bahasa Indonesia sebagai 'anjing betina'. Selain itu, kata bitch dapat pula diterjemahkan menjadi 'perempuan jalang' atau perempuan yang tabiatnya buruk. Namun demikian, tentu penerjemahan frasa my bitch pada larik tersebut akan janggal jika diterjemahkan menjadi "[Aku] membelikan berlian untuk enam anjing betinaku" atau "[Aku] membelikan berlian untuk enam perempuan jalangku". Maka dari itu, peneliti berusaha menerjemahkan kalimat tersebut dengan mencari petunjuk konteks dari pilihan kata lain. Dalam larik ini, peneliti menemukan kata diamond yang bisa dijadikan referensi konteks. Jika kata diamond 'berlian' dibaca sebagai simbol dari barang yang sangat berharga, maka semestinya seseorang membelikan barang berharga kepada orang yang disayangi atau orang yang istimewa. Petunjuk lainnya peneliti dapatkan dari Tweet Grande ketika menjawab pertanyaan dari salah seorang penggemarnya yang mempertanyakan, kepada siapa saja cincin "7 Rings" dibelikan? Gambar 2 berikut merupakan kutipan pos Tweet Grande.

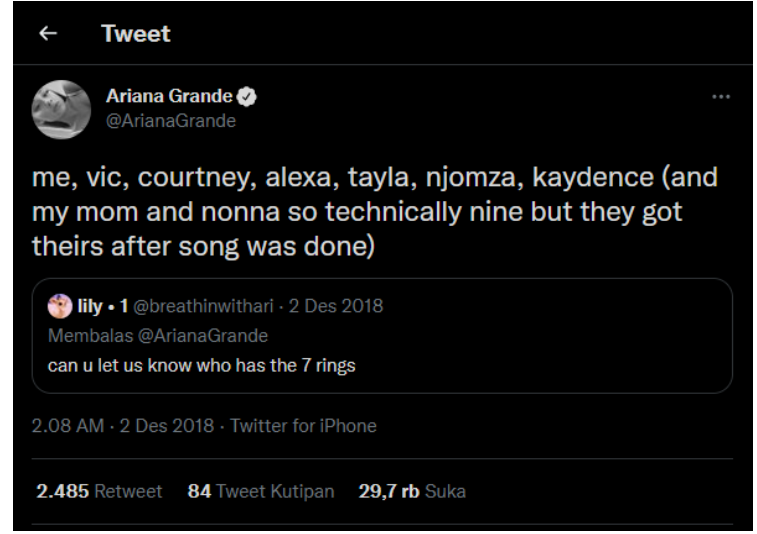

Gambar 2.

Sumber: Twitter Ariana Grande (2018b)

Dalam Tweet tersebut, Grande menjawab bahwa ketujuh cincin berlian yang dibelinya dibagikan kepada enam orang sahabatnya yang juga menjadi penulis lirik lagu tersebut. Maka dari itu, peneliti menerjemahkan larik tersebut menjadi "[Aku] membelikan berlian untuk enam perempuan kesayanganku." Pemaknaan secara konotatif dari larik tersebut menunjukkan adanya representasi perilaku gaya hidup konsumerisme dan hedonisme. Perilaku tersebut disimbolkan melalui pembelian berlian untuk enam orang sekaligus. Berlian adalah batu mulia yang harganya sangat mahal. Membali satu berlian saja tentu membutuhkan uang yang tidak sedikit.

Pada larik ketiga, terdapat kalimat "I'd rather spoil all my friends with my riches" yang dapat diartikan "Aku lebih suka memanjakan semua teman-temanku dengan kekayaanku'. Kemudian pada larik keempat, terdapat kalimat "Think retail therapy my new addiction" yang dapat diterjemahkan 'Sepertinya terapi belanja [adalah] kecanduanku yang baru'. Jika dimaknai secara denotatif, larik ketiga menggambarkan perilaku orang yang suka membahagiakan teman-temannya dengan kekayaan atau uang. Jelas bahwa orang tersebut adalah orang yang kaya raya karena mampu menggunakan uang tanpa banyak berpikir, semata-mata untuk mengejar kebahagiaan, dan merasa puas ketika mampu melakukan itu semua. Secara konotatif, perilaku membelanjakan uang tanpa banyak berpikir dan berfoya-foya adalah representasi orang yang memiliki gaya hidup konsumerisme dan hedonisme.

Jika kalimat larik keempat dimaknai secara denotatif, kalimat tersebut adalah sebuah pernyataan bahwa perilaku berbelanja secara berlebihan adalah sebuah terapi atau pengobatan yang justru membuat kecanduan. Piliang (2011:90) mengutip pendapat Lasch yang menyebutkan bahwa salah satu ciri masyarakat konsumer adalah bersifat terapis, dalam artian berusaha untuk 
memenuhi dan memuaskan diri melalui terapiterapi yang sebenarnya hanya berefek sementarakepuasan yang diberikan tidak jangka panjang apalagi kekal. Dengan demikian, jika dimaknai secara konotatif, kalimat ini merepresentasikan gaya hidup masyarakat konsumerisme dan hedonisme.

\section{Analisis Bait VI}

Seperti halnya bait $\mathrm{V}$, larik pada bait VI juga cenderung eksplisit menyebutkan perilaku konsumerisme. Larik pertama berbunyi "Whoever said money can't solve your problems" bersambung dengan larik kedua "Must not have had enough money to solve 'em'. Jika diterjemahkan, kedua kalimat tersebut diartikan 'Siapa pun yang menganggap bahwa uang tak dapat menyelesaikan masalah, pasti tidak punya cukup uang untuk menyelesaikan masalahnya.' Pemaknaan secara denotatif kalimat-kalimat ini memperlihatkan penolakan terhadap maksim bahwa uang tidak selamanya menyelesaikan masalah dan menegaskan bahwa justru uang dapat menyelesaikan masalah, asalkan kita mempunyai uang untuk menyelesaikan masalah itu.

Pandangan seperti ini bisa dianggap sebagai pandangan angkuh orang kaya ketika memandang masalahnya. Namun begitu, pandangan seperti ini memang nyata terjadi dan diakui sendiri di kalangan orang-orang dengan sumber daya finansial yang besar atau memiliki uang banyak. Elkins (2015) menunjukkan sebuah hasil studi yang dilaksanakan Steve Siebold terhadap 1.200 orang kaya di dunia, yaitu orang-orang kaya memang mengakui bahwa uang dapat menyelesaikan hampir semua masalah. Secara konotatif, pandangan hidup bahwa uang dapat menyelesaikan masalah adalah sebuah prinsip yang sejalan dengan gaya hidup konsumerisme. Dengan membelanjakan uang, orang dapat menyelesaikan masalah, mendapat ketenangan hidup, dan mencapai kepuasan diri.

\section{Analisis Bait X}

Bait X lirik lagu "7 Rings" adalah bagian verse ketiga yang ketika dinyanyikan nadanya berbeda dari bagian verse lain. Bagian ini dinyanyikan dengan gaya rap yang menggunakan artikulasi cepat. Pada larik pertama, terdapat kalimat "Go from the store to the booth" yang bisa diartikan 'Berpindah dari toko ke ruang ganti'. Kemudian, pada larik kedua "Make it all back in one loop, give me the loot" dapat diartikan 'Lakukan semuanya dalam satu kali putaran, berikan aku semua barang itu'. Secara denotatif, lirik ini mendeskripsikan perilaku seseorang berbelanja dalam jumlah banyak dan tidak berpikir panjang. Orang yang begitu melihat barang di pajangan toko langsung mencoba dan langsung membelinya adalah karakter yang tidak banyak berpikir tentang uang ketika berbelanja. Secara konotatif, perilaku ini adalah contoh perilaku konsumerisme.

Pada larik ketiga, ditemukan kalimat "Never mind, I got the juice." Kalimat ini dapat diterjemahkan menjadi 'Jangan khawatir, aku punya uangnya'. Kata juice dalam pemaknaan formal memang berarti 'minuman'. Namun begitu, dalam bahasa ragam slang, dapat diartikan sebagai 'uang' (Dalzell, 2018). Pemaknaan secara denotatif kalimat ini menunjukkan rasa tidak khawatir seseorang tentang kehabisan uang. Jika dikaitkan dengan larik-larik sebelumnya yang memaparkan tentang perilaku membeli barang tanpa berpikir panjang, secara konotatif larik ini dapat dimaknai sebagai sebuah penegasan bahwa uang dalam kehidupan orang yang berpandangan konsumerisme dan hedonisme bukanlah hal yang penting, selama dengan uang mereka bisa mendapatkan kebahagiaan dan kesenangan.

Selanjutnya pada larik kelima terdapat kalimat "Look at my neck, look at my jet". Kalimat ini dapat diterjemahkan "Lihat leherku, lihat jetku." Jika dimakna secara denotatif, kalimat ini adalah sebuah kalimat perintah yang meminta agar seseorang memerhatikan leher dan jet seseorang lain. Mengapa meminta melihat leher? Apa yang harus dilihat di leher? Jika dikaitkan dengan konteks bahwa lirik lagu ini sebagian besar memamerkan kepemilikan si tokoh $I$ atau me, bisa diasumsikan bahwa tokoh $I$ meminta untuk melihat sesuatu yang mewah di leher $I$-misalnya kalung atau perhiasan mahal. Secara konotatif, kalimat ini merepresentasikan seseorang yang ingin memamerkan segala kekayaan materi yang dimilikinya.

Kemudian pada larik keenam, terdapat kalimat yang berbunyi "Aint got enough money to pay me respect" dan bersambung dengan larik ketujuh, "Ain't got enough money when I'm on the set." Kedua kalimat ini dapat diartikan "Tak cukup uang untuk menghormatiku//Tak cukup uang ketika aku berada di tempat//"'. Pemaknaan secara denotatif kalimat tersebut dapat dipahami sebagai pernyataan (statement) seseorang yang menyatakan bahwa dirinya lebih mulia atau lebih berharga daripada uang. Sikap ini merepresentasikan sifat narsistik bahwa tidak ada yang lebih mulia daripada dirinya. Namun jika demikian, terbentuk sebuah premis yang menarik. Di satu sisi, orang yang dibicarakan dalam lirik tersebut mengagungkan harta, materi, dan uang sebagai simbol kebahagiaan hidupnya (hedonistik), namun di sisi lain dia 
menganggap dirinya lebih mulia daripada uang itu sendiri (narsistik). Pembacaan makna secara konotatif lagi-lagi mengungkapkan bahwa perilaku narsistik yang menyatakan dirinya lebih mulia daripada uang adalah representasi dari ideologi hedonisme.

\section{Mitos Gaya Hidup Hedonisme dan Konsumerisme dalam Lirik "7 Rings"}

Seperti yang telah dikemukakan di depan, Grande mengakui bahwa lirik lagi "7 Rings" ditulis oleh dirinya dan keenam sahabatnya sepulang dari bersenang-senang. Grande membeli 9 pasang cincin berlian, satu untuk dirinya, enam untuk sahabatnya, dan 2 lagi untuk keluarganya. Namun begitu, rujukan "7 Rings" atau tujuh cincin berlian yang dimaksud Grande dalam lirik lagu itu mengarah kepada cincin yang dibeli untuknya dan untuk keenam sahabatnya. Grande menyebut bahwa cincin berlian itu sebenarnya adalah cincin pertunangan, namun akhirnya menyebut ketujuh cincin tersebut sebagai cincin tanda persahabatan. Selain itu, di akun Twitternya, Grande juga menyebutkan bahwa latar peristiwa yang terjadi dalam narasi "7 Rings" adalah setelah ia mengalami peristiwa "buruk" (disebutnya sebagai bad days) dalam kehidupannya. "7 Rings" dan kejadian di balik penciptaan lirik itu-tentang Grande dan sahabatnya pergi ke Tiffany kemudian mabuk dan membeli 9 pasang cincin-adalah sebuah upaya Grande menghibur diri, memulihkan suasana hati, atau untuk melupakan pengalaman buruk tersebut.

Penjelasan Grande ini diamini oleh kebanyakan media yang membahas tentang maksud di balik simbol tujuh cincin yang menjadi judul dan disebut dalam lirik (Gonzales, 2019; HarveyJenner, 2019; Prance, 2019). Adanya acknowledgement dari media, khususnya situs-situs berita hiburan dan dunia selebritas, membuat fans Grande meyakini bahwa lirik lagu "7 Rings" memang membawa tema persahabatan dan pemulihan suasana hati Grande. Pada titik ini, pemahaman tersebut menjadi sebuah mitos, yang diproduksi oleh si pembuat lagu dan dikonsumsi oleh para pendengarnya, terutama para fans. Namun begitu, seiring berjalannya waktu, rupanya mitos itu terbongkar dengan sendirinya.

Seperti halnya yang telah diungkapkan dalam pemaknaan secara denotatif dan konotatif di bagian sebelumnya, sebagian besar larik dalam teks lirik "7 Rings" justru merepresentasikan gaya hidup konsumerisme dan hedonisme. Gaya hidup itu direpresentasikan dalam perilaku-perilaku seperti membeli tujuh cincin berlian untuk teman-teman, makan di kafe mewah, bahkan menolak gagasan bahwa uang tidak bisa menyelesaikan masalah.
Pada awalnya, pendengar lagu tersebut menerima penjelasan Grande tentang makna persahabatan di balik "7 Rings". Namun begitu, setelah mencoba memahami kembali lirik lagu tersebut, beberapa orang mulai berubah pemahaman dan menolak pemahaman Grande sendiri sebagai penulis lagu. Beberapa contoh penolakan itu bisa dilihat di beberapa pos media sosial.

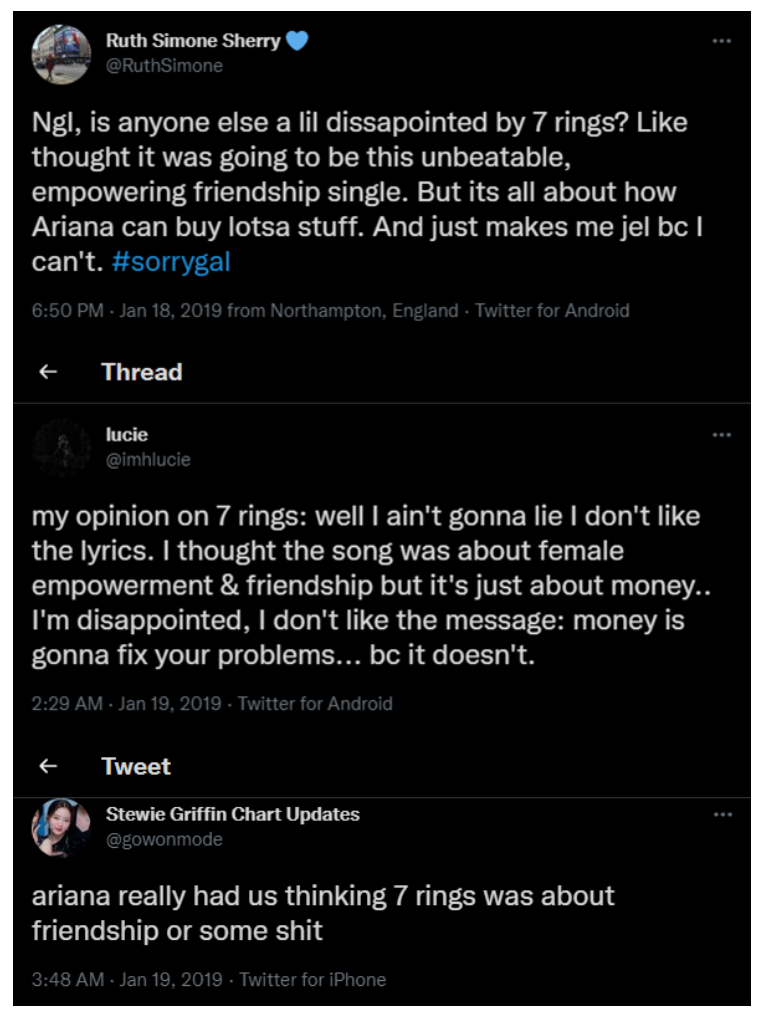

Sumber: Twitter (2019)

Gambar 4. Contoh penolakan pemaknaan lirik lagu

"7 Rings" sebagai simbol persahabatan.

Di titik ini, rupanya terjadi dekonstruksi mitos, bahwa yang awalnya lagu "7 Rings" dipahami sebagai sebuah simbolisasi kekuatan persahabatan yang mampu mengatasi masalah seseorang, ternyata dibongkar, kemudian dikonstruksi ulang menjadi pemahaman baru, yaitu pameran kekayaan, perilaku konsumerisme, dan gaya hidup hedonis yang dimiliki oleh orang yang memiliki uang banyak-seperti Grande misalnya, sebagai seorang superstar.

\section{KESIMPULAN}

Berdasarkan hasil analisis dan pembahasan yang telah dipaparkan pada bagian sebelumnya, dan dengan menghubungkannya dengan rumusan masalah yang telah dijabarkan di depan, dapat ditarik simpulan seperti berikut. 
Lirik lagu "7 Rings" karya Ariana Grande mengandung banyak tanda yang berkaitan dengan konsep hedonisme, atau mengejar kesenangan material, yang dianut oleh kaum muda Amerika Serikat. Tanda-tanda ini ditemukan dalam bentuk kalimat atau frasa yang menunjukkan perilaku mengagungkan harta dan materi, membelanjakan uang untuk memuaskan diri atau orang lain, dan memamerkan segala kekayaan yang dimiliki diri sendiri dan tidak dimiliki orang lain sebagai justifikasi bahwa dirinya memang lebih baik daripada orang lain.

Dalam kerangka analisis semiotika dikotomis Barthes, kalimat-kalimat dalam lirik lagu "7 Rings" adalah penanda atau expression yang dapat dibaca maknanya (petandanya) secara denotatif. Kemudian, makna denotatif dari masing-masing kalimat tersebut juga berfungsi sebagai penanda jika dibaca secara konotatif. Makna dari kalimat-kalimat lirik itu ternyata dapat dipahami berbeda.

Tabel 2. Peta Pemaknaan Denotatif dan Konotatif Ideologi dalam Lirik Lagu "7 Rings".

\begin{tabular}{|c|c|c|}
\hline $\begin{array}{l}\text { 1. Penanda } \\
\text { - Kalimat- } \\
\text { kalimat } \\
\text { dalam } \\
\text { lirik lagu } \\
\text { "7 Rings" }\end{array}$ & $\begin{array}{l}\text { 2. Petanda } \\
\text { - membeli } \\
\text { semua barang } \\
\text { yang disuka } \\
\text { - menulis cek } \\
\text { sesuka hati } \\
\text { - membeli } \\
\text { kecantikan } \\
\text { (penampilan) } \\
\text { fisik } \\
\text { - membeli } 7 \\
\text { pasang cincin } \\
\text { berlian } \\
\text { - menganggap } \\
\text { uang bisa } \\
\text { menyelesaikan } \\
\text { semua } \\
\text { masalah } \\
\text { - berlbelanja } \\
\text { tanpa banyak } \\
\text { berpikir } \\
\text { - memamerkan } \\
\text { perhiasan dan } \\
\text { kendaraan } \\
\text { pribadi yang } \\
\text { mahal } \\
\text { - apapun yang } \\
\text { diinginkan } \\
\text { pasti dibeli }\end{array}$ & \\
\hline \multicolumn{2}{|c|}{$\begin{array}{l}\text { 3. Tanda } \\
\text { I. PENANDA }\end{array}$} & $\begin{array}{l}\text { II. } \\
\text { PETANDA }\end{array}$ \\
\hline
\end{tabular}

\begin{tabular}{|l|l|}
\hline Perilaku-perilaku yang & Perilaku \\
menghambur-hamburkan & konsumer- \\
uang, tidak hemat, & isme yang \\
memamerkan harta & memuaskan \\
kekayaan & $\begin{array}{l}\text { diri dengan } \\
\text { berbelanja } \\
\text { untuk } \\
\text { mendapatkan } \\
\\
\text { segala yang } \\
\text { diinginkan }\end{array}$ \\
\hline Sikap dan gaya hidup hedonisme \\
\hline
\end{tabular}

Oleh Grande sebagai penyanyi sekaligus salah satu dari penulisnya menyebutkan bahwa lirik lagu "7 Rings" merupakan simbol persahabatan antara Grande dan sahabatsahabatnya yang menemani dan menghiburnya setelah melewati pengalaman buruk dalam kehidupan. Namun begitu, kalimat-kalimat dalam lirik lagu "7 Rings" juga bisa dimaknai sebagai representasi perilaku berfoya-foya, mengagungkan kekayaan material, sekaligus membuang-buang harta itu sendiri. Perilaku ini secara konotatif adalah representasi dari ideologi masyarakat konsumerisme dan hedonistik.

\section{REFERENSI}

Aviandy, M., \& Saleh, M. I. (2020). Representasi Ideologi Generasi Muda Uni Soviet dalam Lirik Lagu Mama-Anarxija (Mama Anarki) dari Kino. JSSH (Jurnal Sains Sosial dan Humaniora), 4(2), 121-138.

Barker, C. (2016). Cultural Studies: Teori \& Praktik. Kreasi Wacana.

Bauman, Z. (2007). Consuming Life. Polity Press.

Bowenbank, S. (2019). A Guide To Who Ariana Grande's Friends In "7 Rings" Are. Elle.com. https://www.elle.com/culture/music/a2593858 0/ariana-grande-friend-group-7-rings/

Dalzell, T. (Ed.). (2018). The Routledge Dictionary of Modern American Slang and Unconventional English. Routledge.

Djajasudarma, T. F. (2010). Metode Linguistik: Ancangan Metode Penelitian dan Kajian. Refika Aditama.

Feldman, F. (2004). Pleasure and The Good Life. Oxford University Press.

Gonzales, E. (2019). The True Story Behind Ariana Grande's New Hit, "7 Rings." Harpers Bazaar.

https://www.harpersbazaar.com/culture/artbooks-music/a25948050/ariana-grande-7rings-lyrics-meaning/

Harvey-Jenner, C. (2019). Ariana Grande explained the meaning behind her new song, 7 Rings. Cosmopolitan.com. 
Ichsanuddin, \& Purnomo, H. (2021). Sosial, Variasi Produk Terhadap Keputusan Pembelian Melalui Citra Merek. Media Sains Indonesia.

Kurniullah, A. Z., Faried, A. I., Saragih, H., Wisnujati, N. S., Amruddin, Syafrizal, Yusa, I. M. M., Hasnidar, Daud, \& Prijanto, J. H. (2021). Pembangunan dan Perubahan Sosial. Yayasan Kita Menulis.

Leading music genres according to consumers in the United States as of May 2018. (2021). Statista.com. https://www.statista.com/statistics/442354/mu sic-genres-preferred-consumers-usa/

Piliang, Y. A. (2011). Dunia Yang Dilipat: Tamasya Melalui Batas-Batas Kebudayaan (Edisi 3 Plus DVD) (3 ed.). MATAHARI.

Piliang, Y. A., \& Jaelani, J. (2018). Teori Budaya Kontemporer: Penjelajahan Tanda \& Makna. Cantrik Pustaka.

Prance, S. (2019). Ariana Grande raps about her ass in her "7 Rings" lyrics and it's iconic. Popbuzz.com.

https://www.popbuzz.com/music/artists/ariana -grande/news/7-rings-lyrics-meaning/

Prasetio, A. (2013). PREFERENSI MUSIK DI KALANGAN REMAJA. Jurnal Pengkajian, Penyajian, dan Penciptaan Musik, 1(1), 7592.

Scarpi, D. (2020). Hedonism, Utilitarianism, and Consumer Behavior. Palgrave Macmillan.

Setiowati, E., \& Wahyuningtyas, B. P. (2011). Marjinalisasi Perempuan Pertama Melalui Lagu: Suatu Analisis Wacana Kritis Terhadap Lagu "Jadikan Aku Yang Kedua." Humaniora, 2(2), 1006-1024.

Sudjatmiko, H. (2007). Saya Berbelanja Maka Saya Ada. Jalasutra.

Sulastianto, H., Tambrin, I., Tarjo, E., Karyati, D., Supratna, N., Sukmayadi, Y., \& Barnas, B. (2006). Seni Budaya (Grafindo M).

Tambayong, Y. (2011). Pak Presiden Menyanyi. Kepustakaan Populer Gramedia.

Zaid, H., Sudiana, Y., \& Wibawa, R. S. (2021). Kritik Sosial Terhadap Fenomena Media
Sosial Melalui Lirik Lagu "Komodifikasi" Karya Grup Musik Feast. In Teori Komunikasi dalam Praktik (hal. 2-14). Zahira Media Publisher.

\section{Pos Media Sosial}

A. [@walkmetomycar]. (2019, June 26). can't believe I once thought 7 rings would be a ballad-like song about friendship . [Tweet]. Twitter.

https://twitter.com/walkmetomycar/status/1143 723555865137152

Grande, A. [@ ArianaGrande]. (2018, December 2). well ............ 'twas a pretty rough day in nyc. my friends took me to tiffany's. we had too much champagne. I bought us all rings. $\delta$ it was very insane and funny. \& on the way back to the stu njomza was like 'bitch, this gotta be a song lol'. so we wrote it that afternoon. [Tweet]. Twitter. https://twitter.com/arianagrande/status/106893 $\underline{1259043205120}$

Grande, A. [@ ArianaGrande]. (2018, December 2). me, vic, courtney, alexa, tayla, njomza, kaydence (and my mom and nonna so technically nine but they got theirs after song was done) [Tweet]. Twitter. https://twitter.com/ArianaGrande/status/10689 29900856279040

lucie. [@imhlucie]. my opinion on 7 rings: well I ain't gonna lie I don't like the lyrics. I thought the song was about female empowerment \& friendship but it's just about money.. I'm disappointed, I don't like the message: money is gonna fix your problems... bc it doesn't. (2019, January 19). [Tweet]. Twitter. https://twitter.com/imhlucie/status/1086329783 $\underline{208665089}$

Stewie Griffin Chart Updates. [@gowonmode]. (2019, Januari 19). ariana really had us thinking 7 rings was about friendship or some shit. [Tweet]. Twitter. https://twitter.com/gowonmode/status/1086349 553811496961 